\title{
cmaJOPEN
}

\section{Disability-free survival after major cardiac surgery: a population-based retrospective cohort study}

\author{
Louise Y. Sun MD SM, Anan Bader Eddeen MSc, Thierry G. Mesana MD PhD
}

\section{Abstract}

Background: Cardiovascular research has traditionally been dedicated to "tombstone" outcomes, with little attention dedicated to the patient's perspective. We evaluated disability-free survival as a patient-defined outcome after cardiac surgery.

Methods: We conducted a retrospective cohort study of patients aged 40 years and older who underwent coronary artery bypass grafting (CABG) or single or multiple valve (aortic, mitral, tricuspid) surgery in Ontario between Oct. 1, 2008, and Dec. 31, 2016. The primary outcome was disability (a composite of stroke, 3 or more nonelective hospital admissions and admission to a long-term care facility) within 1 year after surgery. We assessed the procedure-specific risk of disability using cumulative incidence functions, and the relative effect of covariates on the subdistribution hazard using Fine and Gray models.

Results: The study included 72824 patients. The 1-year incidence of disability and death was 2431 (4.6\%) and 1839 (3.5\%) for CABG, 677 (6.5\%) and 539 (5.2\%) for single valve, $118(9.0 \%)$ and 140 (10.7\%) for multiple valve, $718(9.0 \%)$ and 730 (9.2\%) for CABG and single valve, and 87 (13.1\%) and 94 (14.1\%) for CABG and multiple valve surgery, respectively. With CABG as the reference group, the adjusted hazard ratios for disability were $1.34(95 \%$ confidence interval $[\mathrm{Cl}] 1.21-1.48)$ after single valve, $1.43(95 \%$ Cl 1.18-1.75) after multiple valve, 1.38 (95\% Cl 1.26-1.51) after CABG and single valve, and 1.78 (95\% Cl 1.43-2.23) after CABG and multiple valve surgery. Combined CABG and multiple valve surgery, heart failure, creatinine $180 \mu \mathrm{mol} / \mathrm{L}$ or greater, alcohol use disorder, dementia and depression were independent risk factors for disability.

Interpretation: The cumulative incidence of disability was lowest after CABG and highest after combined CABG and multiple valve surgery. Our findings point to a need for models that predict personalized disability risk to enable better patient-centred care.

ardiac surgery is a growing field, with 2 million procedures currently being performed globally each year. ${ }^{1}$ The last 2 decades have seen important advances in surgical and perioperative care and in improved patient survival. ${ }^{2-4}$ On the other hand, as patients presenting for surgery become increasingly older and frail, they shift their goals and priorities toward how surgery might affect personal freedom and mobility, rather than longevity alone. ${ }^{5-9}$ New or residual impairments after surgery are of particular concern to patients and clinicians alike, but the quality and standard of cardiac care has long been assessed by traditional "tombstone" measures such as mortality and major adverse cardiovascular events. ${ }^{5,8,10-12}$ Patient-centred care represents a priority area for modern medical practice and research, and the facilitation of shared surgical decision-making could be improved by incorporating patient perspectives and patient-derived data. ${ }^{13-15}$

Our group has recently derived "disability-free survival" as a patient-defined outcome through a large-scale survey of more than 3000 patients with cardiovascular diseases. ${ }^{16}$ According to patient preferences and values, disability was defined as the composite of stroke, recurrent nonelective hospital admissions and admission to a nursing home. ${ }^{16}$ Before this outcome measure could be meaningfully used to inform patient-centred decision-making, its epidemiology and impact need to be described first at the population level. We therefore conducted the current study to evaluate disability-free survival after major cardiac surgery in a population-based cohort.

\section{Methods}

\section{Design and study population}

We conducted a population-based, retrospective cohort study in Ontario, Canada. We included adults residing in Ontario

Competing interests: None declared.

This article has been peer reviewed.

Correspondence to: Louise Sun, Isun @ ottawaheart.ca

CMAJ Open 2021. DOI:10.9778/cmajo.20200096 
aged 40 years or older and who had undergone CABG, or aortic, mitral or tricuspid valve surgery between Oct. 1, 2008, and Dec. 31, 2016 (Appendix 1, Supplementary Table 1, available at www.cmajopen.ca/content/9/2/E384/suppl/DC1). For those patients who underwent multiple cardiac procedures during the study period, we considered the first procedure to be the index procedure. Exclusion criteria were nonOntario residency status, those with missing information regarding age and sex, and those who had concomitant arrhythmia, or pulmonic valve or thoracic aorta surgery. During the study period, Ontario was Canada's most populous province with a publicly funded, universal health care system that reimburses all covered services and providers.

\section{Data sources}

We used the administrative health care databases from ICES with information on all Ontario residents, and the detailed clinical registry data from CorHealth Ontario. CorHealth Ontario maintains a prospective registry of all patients who undergo invasive cardiac procedures in Ontario. All 20 advanced cardiac hospitals in Ontario participate in the registry. It captures demographic characteristics and comorbidity- and procedural-related information and has been validated through selected chart audits. In addition, ejection fraction and angiographic data in the CorHealth Ontario database undergo core laboratory validation. ${ }^{17}$

We identified individuals who underwent the specified cardiac procedures from the CorHealth Ontario registry, and linked them deterministically to the ICES administrative databases by using encrypted unique confidential codes. Specifically, we linked the date and type of cardiac procedures, physiologic and comorbidity data from CorHealth Ontario with the Canadian Institute for Health Information's Discharge Abstract Database (comorbidities and hospital admissions) and Same Day Surgery database (comorbidities), the Ontario Health Insurance Plan database (physician service claims), the Registered Persons Database (ascertainment of vital statistics), the Continuing Care Reporting System (admissions to long-term care facilities) and the Canadian Census. The administrative databases have been validated for many outcomes, exposures and comorbidities, including heart failure, chronic obstructive pulmonary disease, asthma, hypertension, myocardial infarction and diabetes. ${ }^{18-21}$

\section{Comorbidities}

We identified comorbidities from the CorHealth Ontario registry and supplemented the information with data from the Discharge Abstract Database, Same Day Surgery database and Ontario Health Insurance Plan using International Classification of Diseases, 10th Revision codes $^{22}$ within 5 years before the index procedure, according to validated algorithms. . $^{18,20,23-25}$ We estimated socioeconomic status based on patients' neighbourhood median income in the Canadian Census, and determined their residence (rural v. urban) using the definitions from Statistics Canada. ${ }^{26} \mathrm{We}$ ascertained emergent procedural status from the CorHealth Ontario registry, as cases requiring operative intervention within 48 hours of acute presentation to hospital. We identified height, weight and body mass index from the CorHealth Ontario registry and used it to define class 3 or severe obesity (weight $>159 \mathrm{~kg}$ or body mass index 240). ${ }^{16,25,27,28}$ We identified frailty status using the Johns Hopkins Adjusted Clinical Groups frailty-defining diagnoses indicator, which is an instrument that uses administrative data and is designed and validated for research of frailty-related outcomes and use of resources. ${ }^{28-33}$

\section{Outcomes}

The primary outcome was disability, defined as patientderived composite of stroke, de novo nursing home admission and recurrent nonelective hospital admissions for 3 or more episodes occurring within 1 year of surgery. ${ }^{16}$ Secondary outcomes consisted of all-cause death and each individual component of disability. We identified stroke requiring hospital admission using a validated algorithm with $70 \%$ sensitivity and $99 \%$ specificity. ${ }^{34} \mathrm{We}$ ascertained nonelective hospital admissions using the Discharge Abstract Database, and long-term care admissions using the Continuing Care Reporting System.

\section{Statistical analysis}

Continuous variables were expressed as mean (standard deviation) and categorical variables as number (proportions). We assessed outcomes through Dec. 31, 2017. Patients were censored when they lost possession of a valid Ontario health insurance card. We defined disability-free survival as survival time from the date of index surgery until the date of a disability-defining event, death or last followup, whichever occurred earlier. For patients who had recurrent nonelective hospital admissions, we considered disability to have occurred on the date of the first admission. To account for death as a competing risk, we estimated the cumulative incidence of disability over time using cumulative incidence functions (CIFs), and the relative effect of covariates on the subdistribution hazard using a Fine and Gray model. We explored whether sex had a modifying effect on the relation between disability and type of surgery, by using a multiplicative interaction term of sex $\times$ type of surgery within each of the multivariable time-to-event models. Post hoc, we also examined the cumulative incidence of disability, death, and the composite of these end points, as stratified by age.

We performed analyses using SAS 9.4 (SAS Institute), with statistical significance defined by a 2 -sided $p$ value of $<0.05$. We used the adjusted hazard ratio (HR) and associated $95 \%$ confidence intervals (CIs) to describe the measure of association.

\section{Ethics approval}

The use of data in this project was authorized under section 45 of Ontario's Personal Health Information Protection Act, which does not require review by a research ethics board..$^{35}$ 


\section{Results}

The study included 72824 patients. A flow diagram detailing the process used to select the study cohort is provided in Appendix 1, Supplementary Figure 1. The baseline patient characteristics according to type of surgery are summarized in Table 1. Isolated CABG accounted for $72.2 \%$ of the provincial procedure volume. These were most likely to be performed in younger men with a history of previous myocardial infarction and percutaneous coronary intervention, and least likely to have been performed in those with heart failure.

Compared with those who underwent combined CABG and valve procedures, those who underwent isolated valve surgery were younger and were more likely to have preserved left ventricular ejection fraction and a lower burden of comorbidities, as evidenced by a lower Charlson Comorbidity Index. Further, those who underwent combined CABG and multiple valve surgery were among the frailest and burdened with the highest number of comorbidities.

As we did not observe a statistically significant interaction effect between sex and type of surgery (interaction $p=0.07$ ), subsequent analyses were not stratified by sex.

\section{Disability-free survival}

Table 2 and Supplementary Table 2 in Appendix 1 summarize the cumulative incidence of disability, death and individual disability-defining events according to surgery type. Graphical representations of these events and their subcomponents are provided by surgery type in Figures 1 and 2, and Supplementary Figures 2-4 in Appendix 1. Figure 3 shows the cumulative incidence of disability, death and the combination of these events for all surgeries.

The incidence proportions of disability and death were as follows: $2431(4.6 \%)$ versus $1839(3.5 \%)$ in the CABG-only group; $677(6.5 \%)$ versus $540(5.2 \%)$ in the single valve group; $118(9.0 \%)$ versus $(10.7 \%)$ in the multiple valve group; $718(9.0 \%)$ versus $734(9.2 \%)$ in the CABG and single valve group; and $87(13.1 \%)$ versus $94(14.1 \%)$ in the CABG and multiple valve group. Overall, the 1 -year cumulative incidence of disability was lowest in patients who underwent isolated CABG and highest after CABG and multiple valve surgery. Disability occurred more frequently than death in the year after isolated CABG and single valve surgery. Of those who developed disability, 755 (18.7\%) subsequently died within the year after surgery.

\section{Disability and patient age}

Post hoc, we evaluated the impact of patient age on disability, death and the combination of these events. The cumulative incidence of these events was lowest in adults aged 40-49 years and 50-59 years, and was incrementally higher for each decade above the age of 60 years (Appendix 1, Supplementary Figures 5-7).

\section{Disability-defining events}

The cumulative incidence of stroke, recurrent nonelective hospital admissions and long-term care admissions varied by type of surgery (Table 1 and Appendix 1, Supplementary Figures 2-4). Specifically, the rates of all 3 events were lowest after isolated CABG, highest after combined CABG and multiple valve reconstruction, and were similar after multiple valve surgery and CABG combined with single valve surgery.

\section{Disability risk factors}

The multivariable predictors of disability are summarized in Table 3. With isolated CABG as the reference group, the adjusted subdistribution HRs for disability were 1.34 (95\% CI 1.21-1.48) for single valve, 1.43 (95\% CI 1.18-1.75) for multiple valve, 1.38 (95\% CI 1.26-1.51) for CABG and single valve, and 1.78 (95\% CI 1.43-2.23) for CABG and multiple valve reconstruction. Other statistically significant risk factors of disability were age, female sex, emergent operative status, low income, a history of hypertension, atrial fibrillation, myocardial infarction, heart failure, cerebrovascular disease, peripheral arterial disease, current smoker, chronic obstructive pulmonary disease, diabetes, anemia, renal insufficiency, liver disease, alcohol use disorder, dementia, depression and cancer. Of these, CABG and multiple valve surgery, heart failure, baseline creatinine $180 \mu \mathrm{mol} / \mathrm{L}$ or greater, alcohol use disorder, dementia and depression were the most clinically significant predictors of disability.

\section{Interpretation}

In this population-based study, we systematically described the incidence and risk factors of patient-defined disability after common cardiac procedures. We found that the cumulative incidence of disability was lowest after isolated CABG and highest after CABG and multiple valve surgery. Disability occurred more frequently than death in the year after isolated $C A B G$ and single valve surgery. Combined $C A B G$ and multiple valve surgery, heart failure, baseline creatinine $180 \mu \mathrm{mol} / \mathrm{L}$ or greater, alcohol use disorder, dementia and depression were important predictors of disability in the year after cardiac surgery.

Traditional revascularization trials have sometimes been referred to as "tombstone trials" ${ }^{6}$ because of their focus on death and complications. However, a survey of cardiovascular patients indicated that important outcomes identified by patients were in fact very different compared with those from the clinician's view. ${ }^{16}$ Our findings suggest that most patients who experience disability after cardiac surgery will continue to live with disability. Thus, the incorporation of patient perceptions and values into the design of outcome measures has been proposed as a priority area for cardiovascular research. Such a paradigm shift has been shown to increase the relevance of the research to the end user, speed up the uptake of research into practice and empower patients to make better-informed decisions. ${ }^{36}$

To date, few studies have directly engaged surgical patients to determine what outcomes were meaningful to them, as important end users of the research. Such studies include surveys of noncardiac surgery patients to rank 
Table 1: Baseline characteristics, stratified by type of surgery ${ }^{\star}$

No. (\%) of patients† 


\begin{tabular}{|c|c|c|c|c|c|}
\hline \multirow[b]{2}{*}{ Event } & \multicolumn{5}{|c|}{$\begin{array}{l}\text { Cumulative incidence of events } \\
\%(95 \% \text { confidence interval) }\end{array}$} \\
\hline & $\begin{array}{c}\text { CABG } \\
n=52546\end{array}$ & $\begin{array}{l}\text { Single valve } \\
n=10368\end{array}$ & $\begin{array}{l}\text { Multiple valves } \\
\quad n=1309\end{array}$ & $\begin{array}{c}\mathrm{CABG}+ \\
\text { single valve } \\
n=7936\end{array}$ & $\begin{array}{c}\text { CABG }+ \\
\text { multiple valves } \\
n=665\end{array}$ \\
\hline Disability & $4.6(4.4-4.8)$ & $6.5(6.1-7.0)$ & $9.0(7.5-10.7)$ & $9.0(8.4-9.7)$ & $13.1(10.6-15.8)$ \\
\hline Death & $3.5(3.3-3.7)$ & $5.2(4.8-5.6)$ & $10.7(9.1-12.5)$ & $9.2(8.6-9.9)$ & $14.1(11.6-16.9)$ \\
\hline Disability or death & $7.3(7.1-7.6)$ & $10.4(9.8-11.0)$ & $17.4(15.4-19.5)$ & $16.4(15.6-17.2)$ & $23.8(20.6-27.1)$ \\
\hline Stroke & $1.5(1.4-1.6)$ & $2.5(2.2-2.8)$ & $3.7(2.7-4.8)$ & $3.5(3.1-4.0)$ & $5.7(4.1-7.7)$ \\
\hline$\geq 3$ nonelective hospital admissions & $2.8(2.6-2.9)$ & $3.5(3.2-3.9)$ & $4.4(3.3-5.6)$ & $4.7(4.3-5.2)$ & $6.2(4.5-8.2)$ \\
\hline Long-term care admission & $0.7(0.6-0.7)$ & $1(0.8-1.2)$ & $1.5(1.0-2.3)$ & $1.5(1.3-1.8)$ & $1.8(1.0-3.0)$ \\
\hline
\end{tabular}

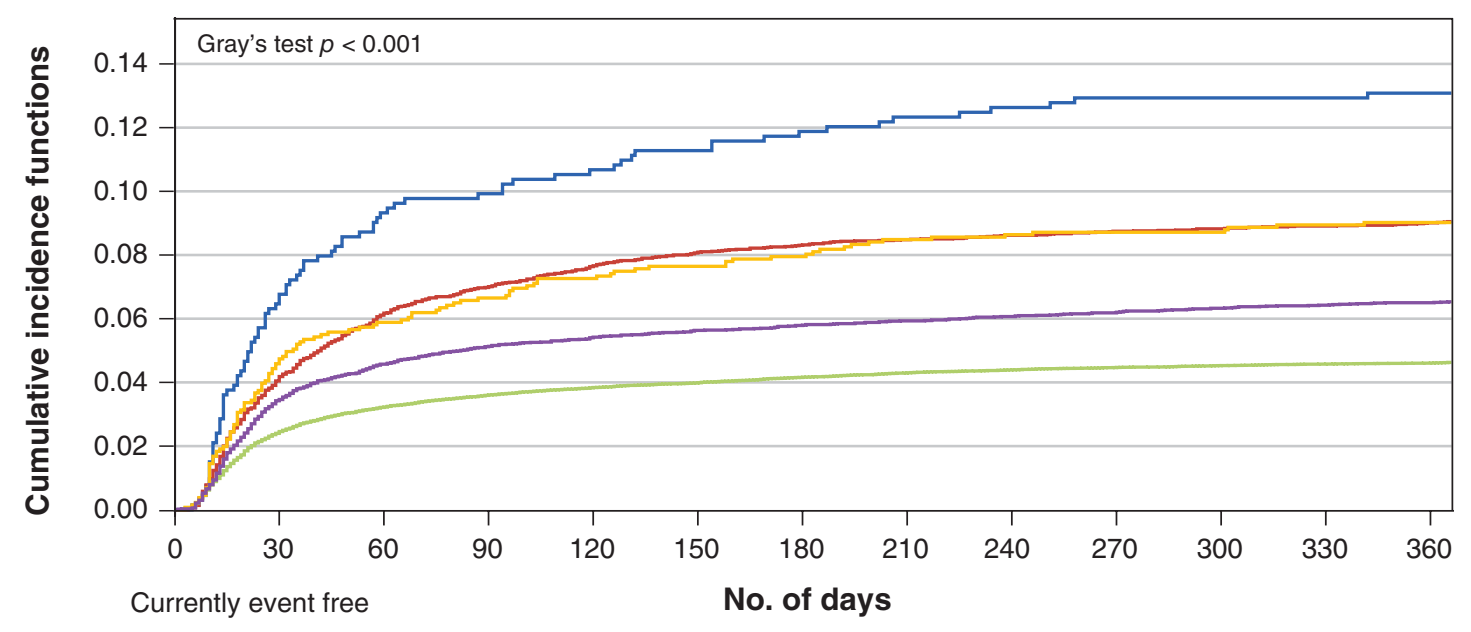

\begin{tabular}{|ll|}
\hline & Surgery \\
CABG + multiple valve & CABG + single valve \\
Multiple valve & Single valve
\end{tabular}

Figure 1: Cumulative incidence of disability within 1 year after cardiac surgery. Note: CABG = coronary artery bypass grafting.

outcomes such as postoperative nausea, vomiting, pain and somnolence in order of unpleasantness, ${ }^{37-39}$ but similar research has not been conducted in the realm of cardiac surgery. "Patient-centred" cardiac surgery research has instead employed standard, clinician-derived instruments (e.g., Seattle Angina Questionnaire, Rose Dyspnea Scale and Patient Health Questionnaire) that were based on expert consensus alone, without active input from patients. ${ }^{40}$ These standard instruments may not be meaningful to all patients as they do not capture all relevant aspects of outcomes after treatment. ${ }^{41}$ Outcomes are an important determinant of treatment satisfaction, and the use of patient-defined outcomes has the unique advantage of improving both patient satisfaction and adherence to treatment.

There is no universal agreement on the definition of disability in cardiovascular research. ${ }^{11}$ Prospective studies using clinician-derived instruments are often limited by small sample size and short follow-up durations, within a single centre 


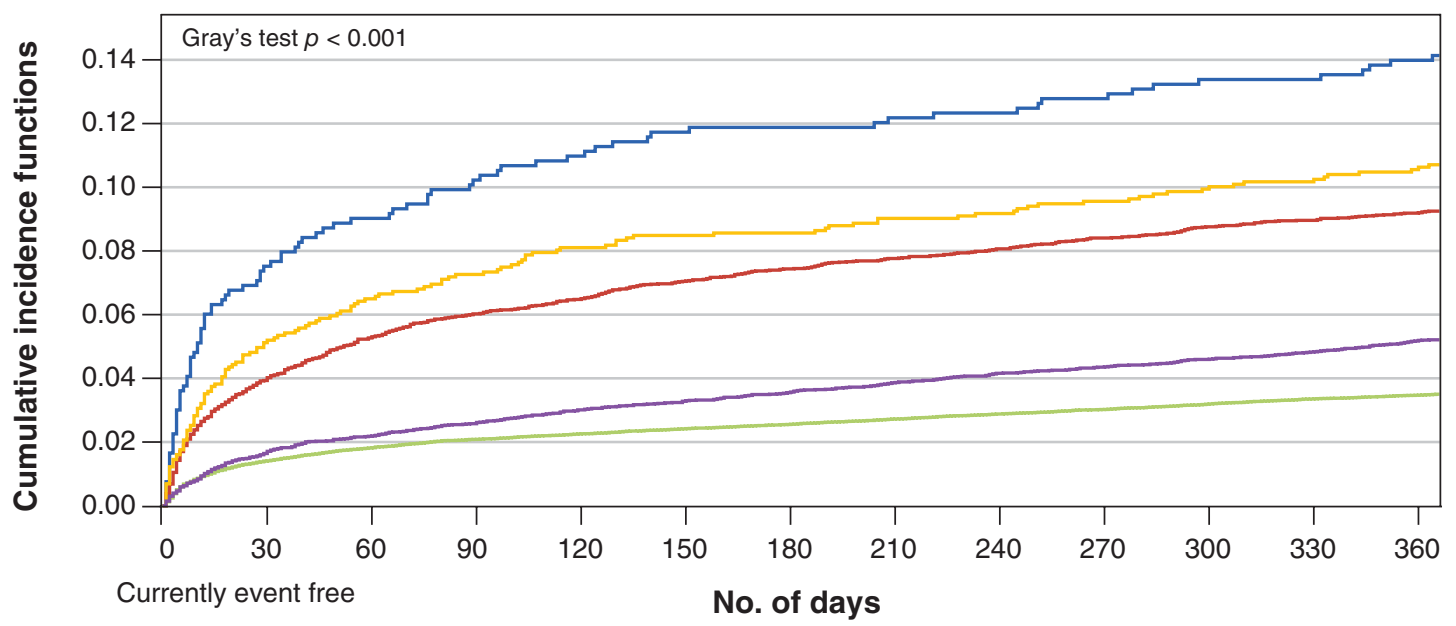

\begin{tabular}{|ll|}
\hline & Surgery \\
CABG + multiple valve & CABG + single valve \\
Multiple valve & Single valve
\end{tabular}

Figure 2: Cumulative incidence of death within 1 year after cardiac surgery. Note: $C A B G=$ coronary artery bypass grafting.

setting. In the present study, we used a new and versatile definition of disability based on patient preferences, ${ }^{16}$ which is adaptable to both prospective trials and large retrospective cohorts. Knowledge generated from this broad epidemiologic study will inform areas of focus for practice-changing research in the future.

CABG is an advancing field in which operative mortality has steadily declined over the years. ${ }^{42}$ This, together with the younger age of presentation for CABG, could explain the lower observed rates of disability after this procedure as compared with complex CABG and multiple valve procedures, which are often performed on older and frailer patients. Complex surgery is associated with greater physiologic stresses such as fluid and electrolyte shifts, prolonged bypass durations, and a higher likelihood of exposure to low cardiac output, hypotension, end organ injury and death. ${ }^{43}$

Single valve surgery, which constitutes mostly operations on the aortic and mitral valves, was associated with a higher incidence of disability than CABG. This observation could be explained by the fact that although patients requiring aortic valve surgery are a mixed population of younger, healthier (e.g., congenital bicuspid aortic valve) and older, sicker candidates (e.g., degenerative aortic valve disease), patients who undergo isolated mitral valve surgery are generally younger, with fewer comorbidities. In contrast, patients who undergo CABG often have other substantial comorbidities that coexist with coronary artery disease to affect their outcomes adversely.
To date, disability after cardiac surgery has been reported in the form of health-related quality of life, using instruments such as the Medical Outcomes Study 36-item Short Form (SF-36), ${ }^{44}$ in several small observational studies. In a singlecentre study of 112 patients, patients reported higher than normative scores in subscales of social functioning, role physical and role emotional; and lower scores in physical function, bodily pain, general health, vitality social function and mental health at 1 year after CABG. ${ }^{45}$ In a study of 534 consecutive patients aged 75 years and older who had undergone cardiac surgery, mean reported quality of life improved at 6 months postoperatively as compared with that at baseline. ${ }^{46}$ In a study of 154 nonagenarians who underwent CABG or valve procedures, $83 \%$ of the survivors reported an improvement in quality of life and $4 \%$ a decline in quality of life 1 year after surgery. ${ }^{47}$

Our findings show that the incidence of patient-defined disability may be greater than that previously described by traditional instruments. Moreover, we were able to describe the population-based incidence of disability by type of surgery and across a wider patient age range. We found that the burden of disability was higher than death after routine procedures such as isolated CABG and single valve surgery, and these findings were driven mostly by recurrent hospital admissions, followed by stroke, especially in those with heart failure, renal dysfunction, alcohol use disorder, dementia and depression. As patients' ability to make informed decisions is often influenced by the emotional and logistical repercussions of their disease 


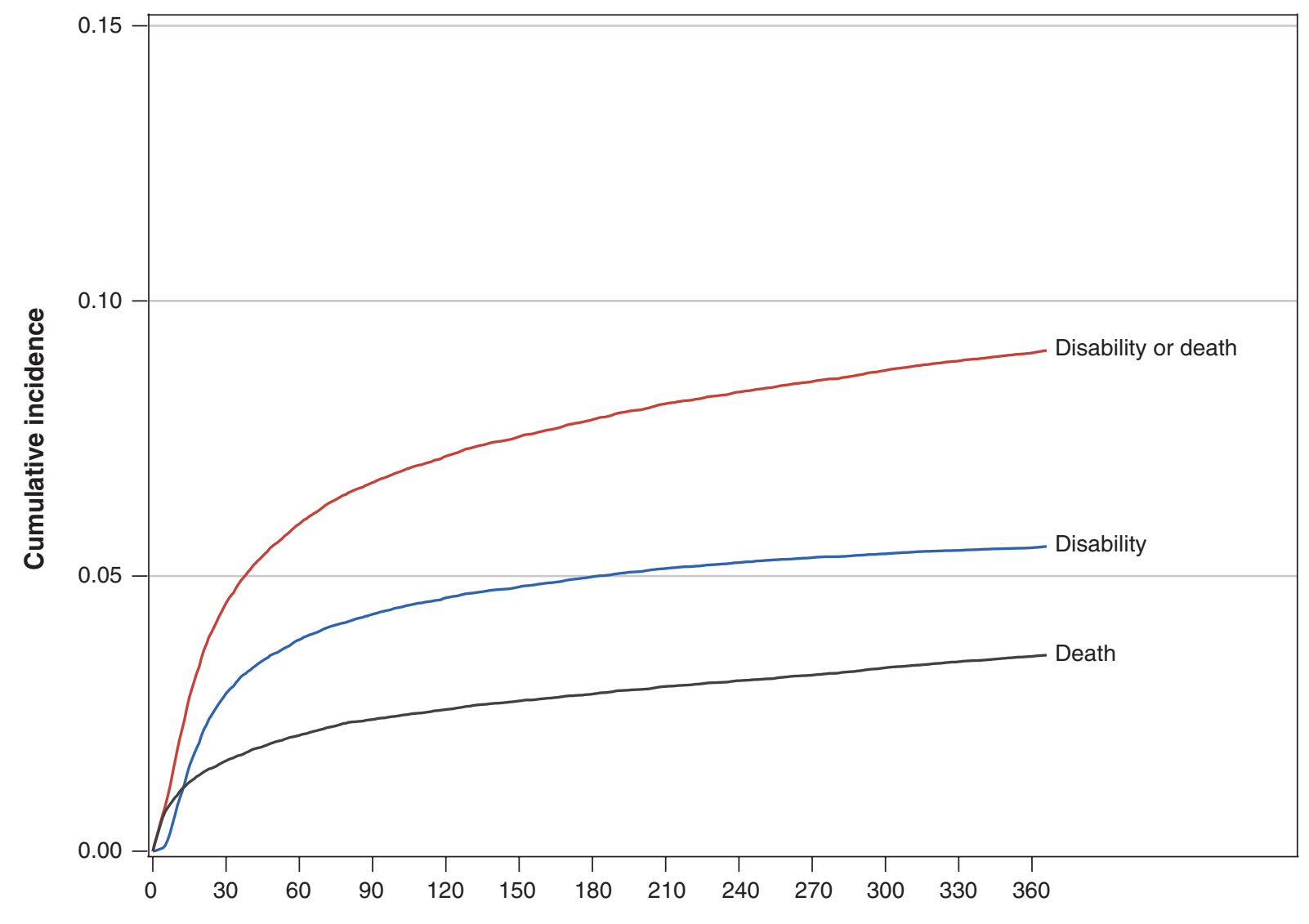

No. of days

Figure 3: Cumulative incidence of disability, death and the combination of these outcomes at 1 year after cardiac surgery.

diagnosis and limitations in health literacy, patients with these high-risk features should be the focus of informed perioperative counselling and undergo formal heart-team evaluation regarding the risks and benefits of alternative treatment strategies.

\section{Limitations}

Although it is possible that we attributed outcomes to the index surgery that may be a consequence of repeat surgery, having a repeat procedure within 1 year of index cardiac surgery is rare. In the present study, of a total of 4031 patients who developed disability during the year after surgery, only $145(3.6 \%)$ had a repeat cardiac procedure before the onset of disability. Repeat procedures may be viewed as a moderator of disability, as patients who are prone to developing disability are also prone to procedure failure.

This study has several limitations. Data pertaining to stroke severity are unavailable in the databases used. As some patients who have a stroke experience full functional recovery, our findings may have overestimated the burden of stroke- related disability. Our definition of disability was based solely on patient perceptions and values. Further studies could aim to elicit feedback from family members and caregivers as well to codefine outcomes, with input and guidance from clinicians. We were unable to incorporate or validate our disability outcome with commonly used clinical disability assessment tools, as our definition of disability is limited by what is available in administrative data. Finally, cohort studies are by nature subject to residual confounding.

\section{Conclusion}

We studied the procedure-specific incidence of a patientdefined disability outcome in a large cohort of cardiac surgical patients. We found disability to be a more frequent complication than death in the year after isolated CABG and single valve surgeries. In addition, patients who undergo combined CABG and multiple valve surgery, and those who have a history of heart failure, baseline creatinine $180 \mu \mathrm{mol} / \mathrm{L}$ or greater, alcohol use disorder, dementia and depression are at the greatest risk for developing disability. Future research should 


\begin{tabular}{|c|c|}
\hline Variable & Subdistribution HR $(95 \% \mathrm{Cl})$ \\
\hline Age & $1.03(1.02-1.03)$ \\
\hline Female & $1.38(1.28-1.48)$ \\
\hline \multicolumn{2}{|c|}{ Surgery type (Ref.: Isolated CABG) } \\
\hline Single valve & $1.34(1.21-1.48)$ \\
\hline Multiple valves & $1.43(1.18-1.75)$ \\
\hline CABG + single valve & $1.38(1.26-1.51)$ \\
\hline CABG + multiple valves & $1.78(1.43-2.23)$ \\
\hline Emergent procedure & $1.40(1.26-1.57)$ \\
\hline Rural residence & $1.03(0.94-1.12)$ \\
\hline \multicolumn{2}{|l|}{ Income quintile (Ref.: 5 [highest]) } \\
\hline 1 (lowest) & $1.33(1.20-1.47)$ \\
\hline 2 & $1.16(1.05-1.29)$ \\
\hline 3 & $1.11(1.00-1.23)$ \\
\hline 4 & $0.99(0.89-1.10)$ \\
\hline Hypertension & $1.16(1.03-1.31)$ \\
\hline Atrial fibrillation & $1.25(1.14-1.37)$ \\
\hline Heart failure & $1.66(1.53-1.79)$ \\
\hline MI within 30 days & $1.26(1.17-1.36)$ \\
\hline Remote MI & $1.13(1.04-1.23)$ \\
\hline Previous $\mathrm{PCl}$ & $0.94(0.85-1.03)$ \\
\hline \multicolumn{2}{|l|}{ LVEF, \% (Ref.: $\geq 50$ ) } \\
\hline$<20$ & $1.10(0.89-1.36)$ \\
\hline $20-34$ & $1.07(0.99-1.16)$ \\
\hline $35-49$ & $1.00(0.89-1.11)$ \\
\hline Cerebrovascular disease & $1.40(1.29-1.53)$ \\
\hline Peripheral arterial disease & $1.23(1.14-1.34)$ \\
\hline \multicolumn{2}{|l|}{ Smoker (Ref.: Never) } \\
\hline Current & $1.19(1.09-1.30)$ \\
\hline Former & $1.07(0.99-1.15)$ \\
\hline COPD or asthma & $1.32(1.24-1.41)$ \\
\hline Pulmonary circulatory disorder & $1.07(0.91-1.24)$ \\
\hline Severe obesity & $0.97(0.91-1.03)$ \\
\hline Diabetes & $1.38(1.29-1.47)$ \\
\hline Hypothyroidism & $1.10(0.93-1.31)$ \\
\hline Anemia & $1.39(1.28-1.51)$ \\
\hline \multicolumn{2}{|c|}{ Baseline creatinine $(\mu \mathrm{mol} / \mathrm{L} ;$ Ref.: $<120)$} \\
\hline $120-179$ & $1.32(1.21-1.45)$ \\
\hline$\geq 180$ & $1.81(1.57-2.08)$ \\
\hline Dialysis & $1.40(1.19-1.64)$ \\
\hline Liver disease & $1.33(1.06-1.68)$ \\
\hline Alcohol use disorder & $1.68(1.39-2.03)$ \\
\hline Dementia & $1.59(1.13-2.24)$ \\
\hline Depression & $1.66(1.41-1.97)$ \\
\hline Psychosis & $1.05(0.62-1.76)$ \\
\hline Primary cancer & $1.19(1.06-1.34)$ \\
\hline Metastatic cancer & $1.47(1.08-1.99)$ \\
\hline \multicolumn{2}{|c|}{$\begin{array}{l}\text { Note: } \mathrm{CABG}=\text { coronary artery bypass grafting } \mathrm{Cl}=\text { confidence interval, } \mathrm{COPD}=\text { chronic obstructive } \\
\text { pulmonary disease, } \mathrm{HR}=\text { hazard ratio, } \mathrm{LVEF}=\text { left ventricular ejection fraction, } \mathrm{MI}=\text { myocardial infarction } \\
\mathrm{PCl}=\text { percutaneous coronary intervention, Ref. = Reference. }\end{array}$} \\
\hline
\end{tabular}


be dedicated to personalized disability risk prediction to inform better the joint therapeutic decision-making process and, in doing so, to improve the efficiency and effectiveness of health care delivery as well as patient satisfaction.

\section{References}

1. Hu J, Chen R, Liu S, et al. Global incidence and outcomes of adult patients with acute kidney injury after cardiac surgery: a systematic review and metaanalysis. 7 Cardiothorac Vasc Anesth 2016;30:82-9.

2. Favaloro RG. Critical analysis of coronary artery bypass graft surgery: a 30-year journey. 7 Am Coll Cardiol 1998;31:1B-63B.

3. Karim MN, Reid CM, Huq M, et al. Predicting long-term survival after coronary artery bypass graft surgery. Interact Cardiovasc Thorac Surg 2018;26:257-63.

4. Baillot RG, Joanisse DR, Stevens LM, et al. Recent evolution in demographic and clinical characteristics and in-hospital morbidity in patients undergoing coronary surgery. Can f Surg 2009;52:394-400.

5. Myles PS. Meaningful outcome measures in cardiac surgery. 7 Extra Corpor Technol 2014;46:23-7.

6. Chalmers I, Clarke M. Outcomes that matter to patients in tombstone trials. Lancet 2001;358:1649.

7. Selby JV, Beal AC, Frank L. The Patient-Centered Outcomes Research Institute (PCORI) national priorities for research and initial research agenda. 7AMA 2012;307:1583-4.

8. Rahimi K, Malhotra A, Banning AP, et al. Outcome selection and role of patient reported outcomes in contemporary cardiovascular trials: systematic review. BM7 2010;341:c5707. doi: 10.1136/bmj.c5707.

9. Mulley AG. Inconvenient truths about supplier induced demand and unwarranted variation in medical practice. BM7 2009;339:b4073. doi: 10.1136/bmj.b4073.

10. Caine N, Harrison SC, Sharples LD, et al. Prospective study of quality of life before and after coronary artery bypass grafting. BM7 1991;302:511-6.

11. Wenger NK, Froelicher ES, Smith LK, et al. Cardiac rehabilitation as secondary prevention. Agency for Health Care Policy and Research and National Heart, Lung, and Blood Institute. Clin Pract Guidel Quick Ref Guide Clin 1995;Oct:1-23.

12. Chocron S, Etievent JP, Viel JF, et al. Prospective study of quality of life before and after open heart operations. Ann Thorac Surg 1996;61:153-7.

13. Siminoff LA. Incorporating patient and family preferences into evidencebased medicine. BMC Med Inform Decis Mak 2013;13(Suppl 3):S6.

14. Bensing J. Bridging the gap. The separate worlds of evidence-based medicine and patient-centered medicine. Patient Educ Couns 2000;39:17-25.

15. Torgerson DJ, Sibbald B. Understanding controlled trials. What is a patient preference trial? BMF 1998;316:360.

16. Sun LY, Tu JV, Lee DS, et al. Disability-free survival after coronary artery bypass grafting in women and men with heart failure. Open Heart 2018;5:e000911.

17. Tu JV, Ko DT, Guo H, et al; Cardiac Care Network of Ontario's Variations in Revascularization Practice in Ontario Working G. Determinants of variations in coronary revascularization practices. CMA7 2012;184:179-86.

18. Tu K, Campbell NRC, Chen ZL, et al. Accuracy of administrative databases in identifying patients with hypertension. Open Med 2007;1:e18-26.

19. Juurlink D, Preya C, Croxford R, et al. Canadian Institute for Health Information Discharge Abstract Database: a validation study. ICES investigative report. Toronto: Institute for Clinical Evaluative Sciences; 2006.

20. Hux JE, Ivis F, Flintoft V, et al. Diabetes in Ontario: determination of prevalence and incidence using a validated administrative data algorithm. Diabetes Care 2002;25:512-6.

21. Austin PC, Daly PA, Tu JV. A multicenter study of the coding accuracy of hospital discharge administrative data for patients admitted to cardiac care units in Ontario. Am Heart 7 2002;144:290-6.

22. Quan H, Sundararajan V, Halfon P, et al. Coding algorithms for defining comorbidities in ICD-9-CM and ICD-10 administrative data. Med Care 2005;43:1130-9.

23. Gershon AS, Wang C, Guan J, et al. Identifying individuals with physician diagnosed COPD in health administrative databases. COPD 2009;6:388-94.

24. Schultz SE, Rothwell DM, Chen Z, et al. Identifying cases of congestive heart failure from administrative data: a validation study using primary care patient records. Chronic Dis Inj Can 2013;33:160-6.

25. Johnston A, Mesana TG, Lee DS, et al. Sex differences in long-term survival after major cardiac surgery: a population-based cohort study. 7 Am Heart Assoc 2019;8:e013260.

26. du Plessis V, Beshiri R, Bollman RD, et al. Definitions of "rural." Agriculture and rural working paper series, No. 61. Ottawa: Statistics Canada; 2002.

27. Sun LY, Tu JV, Bader Eddeen A, et al. Prevalence and long-term survival after coronary artery bypass grafting in men and women with heart failure and preserved vs reduced ejection fraction. 7 Am Heart Assoc 2018;7:e008902.

28. Tran DTT, Tu JV, Dupuis JY, et al. Association of frailty and long-term survival in patients undergoing coronary artery bypass grafting. 7 Am Heart Assoc 2018;7:e009882.

29. Lieberman AC, Weiner JP. Development and evaluation of the Johns Hopkins University risk adjustment models for Medicare+ Choice plan payment. Baltimore: Johns Hopkins University; 2003.
30. Sternberg SA, Bentur N, Abrams C, et al. Identifying frail older people using predictive modeling. Am 7 Manag Care 2012;18:e392-7.

31. The Johns Hopkins Adjusted Clinical Groups Technical Reference Guide, version 9.0. Baltimore: Johns Hopkins University; 2009.

32. Bronskill S CM, Costa A, et al. Aging in Ontario: an ICES chartbook of health services use by older adults - a technical report. Toronto: ICES; 2010.

33. Bronskill S CX, Gruneir A, Ho M. Health system use by frail Ontario seniors: an in-depth examination of four vulnerable cohorts. Toronto: ICES; 2011.

34. Tu K, Wang M, Young J, et al. Validity of administrative data for identifying patients who have had a stroke or transient ischemic attack using EMRALD as a reference standard. Can 7 Cardiol 2013;29:1388-94.

35. Victor JC, Monto AS, Surdina TY, et al. Hepatitis A vaccine versus immune globulin for postexposure prophylaxis. N Engl 7 Med 2007;357:1685-94.

36. Frank L, Basch E, Selby JV; Patient-Centered Outcomes Research Institute. The PCORI perspective on patient-centered outcomes research. $7 A M A$ 2014;312:1513-4.

37. Macario A, Weinger M, Carney S, et al. Which clinical anesthesia outcomes are important to avoid? The perspective of patients. Anesth Analg 1999;89:652-8.

38. Eberhart LH, Morin AM, Wulf H, et al. Patient preferences for immediate postoperative recovery. Br F Anaesth 2002;89:760-1.

39. Rashiq S, Bray P. Relative value to surgical patients and anesthesia providers of selected anesthesia related outcomes. BMC Med Inform Decis Mak $2003 ; 3: 3$

40. McNamara RL, Spatz ES, Kelley TA, et al. Standardized outcome measurement for patients with coronary artery disease: consensus from the International Consortium for Health Outcomes Measurement (ICHOM). $7 \mathrm{Am}$ Heart Assoc 2015;4:e01767.

41. Revicki DA. Patient assessment of treatment satisfaction: methods and practical issues. Gut 2004;53(Suppl 4):iv40-4.

42. Ferguson TB Jr, Hammill BG, Peterson ED, et al. A decade of change-risk profiles and outcomes for isolated coronary artery bypass grafting procedures, 1990-1999: a report from the STS National Database Committee and the Duke Clinical Research Institute. Society of Thoracic Surgeons. Ann Thorac Surg 2002;73:480-9, discussion 489-90.

43. Sun LY, Chung AM, Farkouh M, et al. Defining a perioperative hypotension threshold in association with stroke in cardiac surgery. [published erratum in Anesthesiology 2019;130:360]. Anesthesiology 2018;129:440-7.

44. Ware JE, Sherbourne CD. The MOS 36-item Short-Form Health Survey (SF36): I. Conceptual framework and item selection. Med Care 1992;30:473-83.

45. Taghipour HR, Naseri MH, Safiarian R, et al. Quality of life one year after coronary artery bypass graft surgery. Iran Red Crescent Med 7 2011;13:171-7.

46. Gjeilo KH, Wahba A, Klepstad P, et al. Survival and quality of life in an elderly cardiac surgery population: 5-year follow-up. Eur 7 Cardiothorac Surg 2013;44:e182-8

47. Caceres M, Cheng W, De Robertis $M$, et al. Survival and quality of life for nonagenarians after cardiac surgery. Ann Thorac Surg 2013;95:1598-602.

Affiliations: The Division of Cardiac Anesthesiology, Department of Anesthesiology and Pain Medicine (Sun), University of Ottawa Heart Institute; the School of Epidemiology and Public Health (Sun), University of Ottawa; the Institute for Clinical Evaluative Sciences (Sun, Bader Eddeen); the Division of Cardiac Surgery, Department of Surgery (Mesana), University of Ottawa Heart Institute, Ottawa, Ont.

Contributors: Louise Sun contributed to conception and design of the study. Louise Sun and Anan Bader Eddeen contributed to data acquisition and analysis. Louise Sun, Anan Bader Eddeen and Thierry Mesana contributed to interpretation of data. Louise Sun drafted the work and Louise Sun, Anan Bader Eddeen and Thierry Mesana revised it critically for important intellectual content. All authors gave final approval of the version to be published and agreed to be accountable for all aspects of the work.

Funding: The authors acknowledge support from an operating grant from the Canadian Institutes of Health Research (Grant \#4752). Louise Sun was named Heart and Stroke Foundation of Canada National New Investigator and is supported by the University of Ottawa Tier 2 Clinical Research Chair in Big Data and Cardiovascular Outcomes and the Ottawa Heart Institute Research Corporation.

Content licence: This is an Open Access article distributed in accordance with the terms of the Creative Commons Attribution (CC BYNCND 4.0) licence, which permits use, distribution and reproduction in any medium, provided that the original publication is properly cited, the use is noncommercial (i.e., research or educational use), and no modifications or adaptations are made. See: https://creativecommons.org/ licenses/by-nc-nd/4.0/

Data sharing: The data set from this study is held securely in coded form at ICES. Although data sharing agreements prohibit ICES from making 
the data set publicly available, access may be granted to those who meet prespecified criteria for confidential access, available at https://www.ices. on.ca/DAS.

Acknowledgement: This study is supported by ICES, which is funded by an annual grant from the Ontario Ministry of Health $(\mathrm{MOH})$ and the Ministry of Long-Term Care (MLTC). The authors acknowledge that the clinical registry data used in this analysis is from participating hospitals through CorHealth Ontario, which serves as an advisory body to the MOHLTC, is funded by the MOHLTC, and is dedicated to improving the quality, efficiency, access and equity in the delivery of the continuum of adult cardiac and stroke care in Ontario, Canada. The authors also acknowledge the usage of data compiled and provided by the Canadian
Institute for Health Information. These data sets were linked using unique encoded identifiers and analyzed at ICES.

Supplemental information: For reviewer comments and the original submission of this manuscript, please see www.cmajopen.ca/content/9/2/ E384/suppl/DC1.

Disclaimer: This study was supported by ICES, which is funded by an annual grant from the Ontario Ministry of Health $(\mathrm{MOH})$ and the Ministry of Long-Term Care (MLTC). The analyses, conclusions, opinions and statements expressed herein are solely those of the authors and do not reflect those of the funding or data sources; no endorsement is intended or should be inferred. 